Gut, 1982, 23, 758-765

\title{
Leucocyte function in ulcerative colitis Quantitative leucocyte mobilisation to skin windows and in vitro function of blood leucocytes
}

\author{
J H WANDALL and V BINDER
}

From the Department of Medical Gastroenterology C, Herlev Hospital, University of Copenhagen, Copenhagen, Denmark

SUMMARY Leucocyte function was evaluated by the in vivo mobilisation to skin windows with chambers and by the chemotactic, phagocytic, and nitro blue tetrazolium reducing capacity of blood leucocytes from 20 patients with ulcerative colitis. The total number of leucocytes mobilised to the chambers after 12 hours did not differ from those in 21 healthy volunteers. After 24 and 48 hours reduced number of leucocytes were mobilised by patients with ulcerative colitis $(\mathrm{p}<0 \cdot 01)$. Correspondingly, the leucocyte migration rates were normal initially but were reduced after 18 hours. Mobilisation in vivo was positively correlated to the blood neutrophil count (Rho: $0.5549 \mathrm{p}<0.02$ ) but unrelated to clinical activity. Blood leucocytes showed reduced random migration in vitro as well as chemotactic response to casein $(\mathrm{p}<0.01)$. Serum independent and dependent phagocytosis did not differ from healthy volunteers. Nitro blue tetrazolium reduction by resting leucocytes was increased $(p<0.01)$ in ulcerative colitis compared with controls. Our findings suggest altered in vivo mobilisation and in vitro migration of leucocytes in ulcerative colitis with increased spontaneous nitro blue tetrazolium reduction reflecting increased generation of potentially tissue damaging agents. The findings probably reflect changes secondary to the disease but which may be important in maintaining the inflammatory process.

Immunological mechanisms are accepted as important pathogenic pathways in ulcerative colitis. ${ }^{1}$ Studies have been reported on the possible significance of circulating antibodies, ${ }^{2}$ antigenantibody complexes, ${ }^{34}$ and on cell mediated immunity. 56 .

To what extent changes occur in the function of neutrophilic granulocytes - the dominant inflammatory cell of acute inflammation - has been the subject of only a few studies.

The neutrophilic granulocytes are important in the primary defence system but are also potent mediators of tissue damage. ${ }^{7}$ They occur inside the colonic epithelial cells in ulcerative colitis ${ }^{8}$ and histochemical studies have demonstrated secretion of lysosomal enzymes from these granulocytes in the early lesion of ulcerative colitis ${ }^{9}$ indicating that they

Address for correspondence: J H Wandall, Department of Medical Gastroenterology B, Fredriksberg Hospital, Ndr. Fasanvej 57, Copenhagen F, DK-2000, Denmark

Received for publication 26 January 1982 possibly damage the epithelium.

The purpose of this investigation was to describe in patients with ulcerative colitis the mobilisation of leucocytes in vivo using a quantitative skin window technique and to study the function of blood leucocytes in vitro - namely, the chemotactic, phagocytic, and oxidative metabolic activity.

\section{Methods}

\section{PATIENTS}

\section{Ulcerative colitis}

Twenty patients with ulcerative colitis, median age 38 years (range $22-73$ years, 12 women and eight men). No patient was on medication at the time of study. Any previous treatment with steroids had been discontinued for more than three months, sulphsalazine for two weeks, and all other drugs for more than one week before the study. All patients had given informed consent before the study.

The diagnosis of ulcerative colitis had been established by previously published criteria. ${ }^{10^{\circ}}$ All 
patients were non-febrile and the disease was moderately active in 12 patients (more than four bowel movements in 24 hours, and/or daily blood in the stools, no constitutional disturbance), slightly active in three (three-four bowel movements in 24 hours, and/or small amounts of blood in the stools less than daily), and inactive in five patients (smaller than or equal to two bowel movements in 24 hours, no visible blood in the stools).

An attempt was made to quantify the disease activity by modifying the clinical activity index for Crohn's disease described by Harvey. ${ }^{11}$ The following criteria were used and the index obtained by summation of the scores:

Clinical condition 0: Well being. 1: Episodes of discomfort less than weekly. 2: General fatigue. 3: General ill being with weight loss.

Number of stools daily Blood or pus 0: Stools without blood or pus. 1: Blood and/or pus less than twice weekly. 2: Blood and/or pus in the stool more than twice weekly but not daily. 3: blood and/or pus daily.

Abdominal pain $\quad 0$ : Rarely. 1: Weekly not daily. 2: Daily.

Extra gastrointestinal manifestations One for each.

With the use of this index patients with inactive disease exhibited indices of 1-3 (median 2), slightly active disease 3-6 (median 5) and moderately active disease 7-16 (median 11).

The disease involved the entire colon in four patients, a substantial part in 10 , and the rectum alone in six. The duration of the disease ranged from newly diagnosed to 32 years (median 7 years).

Control group Twenty-one healthy volunteers 10 women and 11 men, served as controls.

\section{TECHNIQUES}

In vivo leucocyte mobilisation

Epidermal abrasions $\left(1 \cdot 2-4 \cdot 3 \mathrm{~cm}^{2}\right)$ were made with surgical scalpels until the papillary layer was visible as red pin-points. No bleeding was allowed. The abrasion was immediately covered with chambers filled with autologous serum. The chamber medium was drained at fixed intervals and leucocytes collected $^{12}$ and counted in haemocytometers. Leucocyte counts were performed without knowledge of the abraded area. A differential count was also performed by counting 200 consecutive cells in May-Grünwald-Giemsa stained coverslip preparations.

The mobilisation was expressed as the cumulated leucocyte migration - namely, the total number of leucocytes per $\mathrm{cm}^{2}$ after $12,24,36$, and 48 hours. The kinetics of the mobilisation was expressed as the leucocyte migration rate giving the number of leucocytes per hour per $\mathrm{cm}^{2}$.
In vitro methods

Leucocytes were isolated from blood drawn 24 hours after admission to hospital at 8.00 am in patients as well as in the healthy controls. Leucocyte function was measured using techniques previously described in detail. ${ }^{13}$

Chemotactic assay Leucocytes were isolated from heparinised blood ( $10 \mathrm{ml}$ blood; 10 units $/ \mathrm{ml})$ after sedimentation of erythrocytes by methylcellulose (molecular weight 150 000). Leucocytes were collected from the supernatant by centrifugation and resuspended in autologous plasma or washed in Hank's balanced salt solution $\mathrm{pH} 7.3$ and resuspended in the solution. Leucocytes $\left(1.25 \times 10^{6}\right)$ were layered on cellulose ester filters (pore size 3 um), Millipore, in a cytocentrifuge (22 $\mathrm{g}$, five minutes), and placed in modified Boyden chambers $\left(37^{\circ}\right.$, three hours). Casein $(5 \mathrm{mg} / \mathrm{ml}$ in Hank's balanced salt solution (nach Hammerstein, Merck) was chosen as chemoattractant, as its effect is independent of serum factors. Random migration was measured in chambers with Hank's balanced salt solution alone below the filters. After incubation the filters were stained and mounted on microscopic slides and read in a microscope (Leitz Wetzlar Orthoplan, 400x). Migration was quantified by the leading front method giving the maximal migrational distance in micrometer by at least two leucocytes in five random fields, and by a chemotactic index giving the number of leucocytes located 50 um inside the filters per thousand leucocytes on the starting surface. All samples were done in duplicates with mean difference between duplicates $11-17 \%$ by the leading front method and $25-31 \%$ by the chemotactic index.

Phagocytosis Leucocytes from $16 \mathrm{ml}$ citrated blood were isolated after sedimentation of erythrocytes by dextran (molecular weight 250000 ), washed thrice in phosphate buffered saline, and resuspended in calcium-and magnesium-containing buffer. ${ }^{13}$ The leucocyte suspension were placed in. a shaking bath for four minutes and paraffin oil emulsion coloured with Oil Red $\mathrm{O}$ was added. After another four minutes the phagocytosis was stopped, uningested emulsion removed by centrifugation $(500 \mathrm{~g}, 20$ minutes) and the oil phagocytosed extracted into p-dioxane ( $1 \mathrm{ml}$, one hour). The extract was clarified by centrifugation $(1000 \mathrm{~g}$, five minutes) and read colorimetrically $(525 \mathrm{~nm}, 1 \mathrm{~cm}$ light path, Zeiss PM4). The oil phagocytosed was calculated from the extinction value and results given as $\mathrm{mg}$ oil per min per $10^{7}$ phagocytes. Emulsion made with bovine serum albumin was used to measure phagocytosis independent of serum factors. Emulsion made with lipopolysaccharide from $E$. coli 026 B6 (boivin method, Difco) and opsonised with fresh autologous 
serum was used to measure serum dependent phagocytosis. All samples were done in duplicates with difference between duplicates $3-10 \%$.

Nitro blue tetrazolium reduction Reduction of nitro blue tetrazolium to formazan was used as an indicator of the oxidative metabolic activity. Leuococytes were isolated and incubated as in the assay of phagocytosis but the medium contained nitro blue tetrazolium $(0.6 \mathrm{mMol} / \mathrm{l})$. Reduction of nitro blue tetrazolium by resting leucocytes and by leucocytes phagocytosing opsonised lipopolysaccharide emulsion was measured. After incubation the leucocytes were washed and the formazan that was generated was extracted into p-dioxane $\left(1 \mathrm{ml}, 85^{\circ} \mathrm{C}, 25\right.$ minutes $)$ and read colorimetrically $(580 \mathrm{~nm}, 1 \mathrm{~cm}$ light path, Zeiss PM4). The activity of resting leucocytes was expressed as the change in extinction value per 8 min per $10^{7}$ phagocytes. The reduction of nitro blue tetrazolium during phagocytosis was given as the change in extinction value per mg oil phagocytosed after correction for resting leucocyte activity. All samples were done in duplicate with difference between duplicates less than $10 \%$.

\section{Statistical analysis}

Differences between patients and controls were tested with the Mann-Whitney rank sum test and correlations with the Spearman rank correlation test.

\section{Results}

The concentration of blood leucocyte subpopulations (Table 1) in patients with ulcerative colitis did not differ from the healthy control group.

\section{LEUCOCYTE MOBILISATION TEST}

Cumulated leucocyte migration after $12,24,36$, and 48 hours is summarised in Table 2. Within the first 12 hours patients with ulcerative colitis mobilise leucocytes in the same number as healthy volunteers. After 24,36 , and 48 hours a reduced value of cumulated leucocyte migration is found in
Table 2 Cumulated leucocyte migration in ulcerative colitis (N:20) and healthy volunteers (N:21)

\begin{tabular}{lll}
\hline $\begin{array}{l}\text { Hours after start } \\
\text { of skin window }\end{array}$ & $\begin{array}{l}\text { Ulcerative } \\
\text { colitis }\end{array}$ & $\begin{array}{l}\text { Healthy } \\
\text { volunteers }\end{array}$ \\
\hline 12 & $17(10-60)$ & $20(10-34)$ \\
24 & $53(26-109)^{*}$ & $74(50-113)$ \\
36 & $92(47-172)^{*}$ & $145(102-261)$ \\
48 & $131(77-329)^{*}$ & $200(160-413)$ \\
\hline
\end{tabular}

Values given are median value and observed range. ${ }^{*} \mathrm{p}<0 \cdot 01$.

patients with ulcerative colitis. The migration was not correlated to the disease activity, the location or duration. A correlation was found, however, between the cumulated leucocyte migration and the concentration of polymorphonuclear lymphocytes in peripheral blood at 24 hours (Rho: $0.5549 ; \mathrm{p}<0.02$ ) and 48 hours (Rho: $0.5195 ; \mathrm{p}<0.05$ ).

The leucocyte migration rate is a measure of the kinetics of the mobilisation and is depicted in Fig. 1.

Patients with ulcerative colitis mobilise leucocytes at the same rate as healthy volunteers during the first 18 hours after start of the skin window. After eight hours patients with ulcerative colitis even show a trend towards higher values (ulcerative colitis: median $2.44 \times 10^{6}$ leucocytes $/ \mathrm{h} / \mathrm{cm}^{2}$, range $0.93-6.9 \times 10^{6}$; healthy volunteers: median $1.85 \times 10^{6}$ leucocytes $/ \mathrm{h} / \mathrm{cm}^{2}$, range $\left.1.1-5.7 \times 10^{6} 0.05<\mathrm{p}<0 \cdot 1\right)$. After 18 hours the leucocyte migration rate values in patients with ulcerative colitis were persistently lower than in healthy volunteers $(\mathrm{p}<0.01)$.

\section{CELLS IN CHAMBER MEDIUM}

Table 3 gives the relative proportion of leucocytes in the chamber medium after 10-12 and 24-48 hours. The predominant leucocytes found are neutrophilic granulocytes with a significantly lower mean nuclear segmentation in ulcerative colitis compared with healthy volunteers $(\mathrm{p}<0 \cdot 01)$.

Small numbers of macrophages were also found in the chamber medium. After 10-12 hours no differences were found between patients with ulcerative colitis and healthy volunteers. After

Table 1 Leucocyte concentrations in peripheral blood

\begin{tabular}{|c|c|c|c|c|c|c|}
\hline & \multirow[b]{2}{*}{$N$} & \multicolumn{2}{|c|}{ Neutrophil granulocytes } & \multirow[b]{2}{*}{$\begin{array}{l}\text { Lymphocytes } \\
10^{9} / l\end{array}$} & \multirow[b]{2}{*}{$\begin{array}{l}\text { Monocytes } \\
10^{6} / l\end{array}$} & \multirow[b]{2}{*}{$\begin{array}{l}\text { Eosinophils } \\
10^{6} / l\end{array}$} \\
\hline & & $10^{9} / l$ & $\begin{array}{l}\text { Mean nucl. } \\
\text { segments }\end{array}$ & & & \\
\hline $\begin{array}{l}\text { Ulcerative colitis } \\
\text { Healthy volunteers }\end{array}$ & $\begin{array}{l}20 \\
21\end{array}$ & $\begin{array}{l}2.41(1.00-4.48) \\
2.95(1.42-4.49)\end{array}$ & $\begin{array}{l}2 \cdot 9(1 \cdot 5-3 \cdot 6) \\
2 \cdot 5(2 \cdot 1-3 \cdot 4)\end{array}$ & $\begin{array}{l}2 \cdot 00(1 \cdot 28-4 \cdot 62) \\
2 \cdot 04(1 \cdot 20-3 \cdot 85)\end{array}$ & $\begin{array}{l}172(0-780) \\
194(0-682)\end{array}$ & $\begin{array}{l}117(0-755) \\
85(0-284)\end{array}$ \\
\hline
\end{tabular}

Values given are median and observed range. No significant differences were found. 


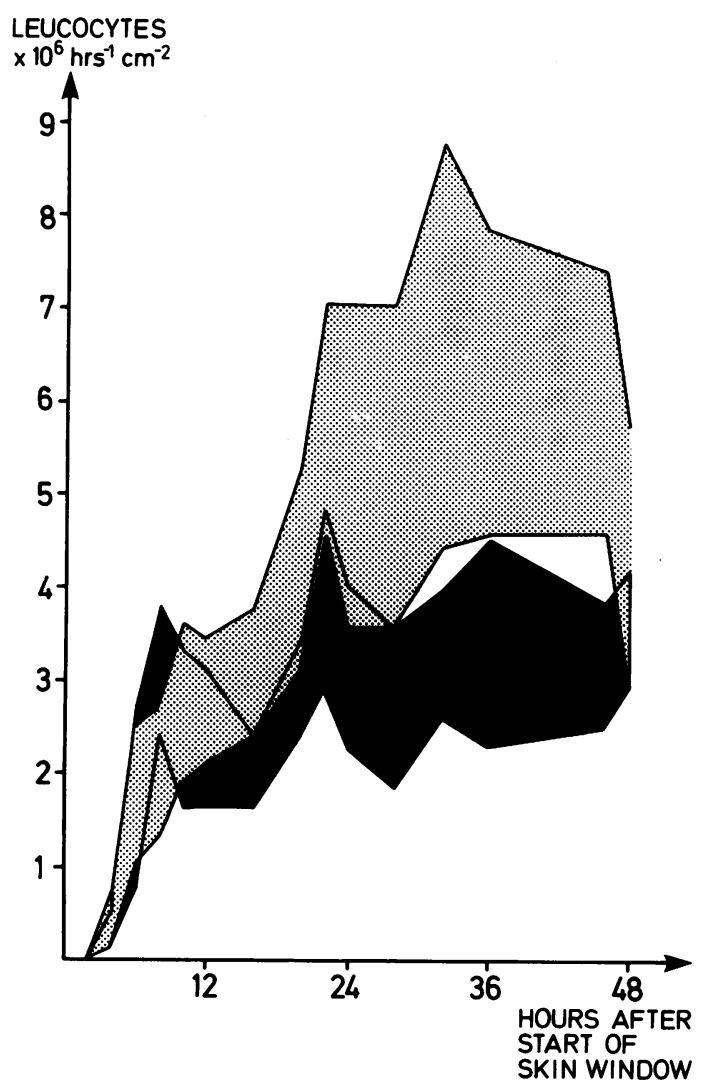

Fig. 1 Leucocyte migration rate in patients with ulcerative colitis $(N: 20)$ and healthy volunteers $(N: 21)$. Values given are the 25/75 percentile. Patients with ulcerative colitis exhibit reduced values from 18 hours after start $(p<0.01)$. ulcerative colitis healthy volunteers.
24-28 hours a reduced relative proportion and number of macrophages were found in ulcerative colitis (ulcerative colitis: median $0.01 \times 10^{\circ}$ macrohages $/ \mathrm{h} / \mathrm{cm}^{2}$, range $0.0-0.09 \times 10^{6} ;$ healthy volunteers: median $0.09 \times 10^{6}$ macrophages $/ \mathrm{h} / \mathrm{cm}^{2}$, range $\left.0 \cdot 0-0.49 \times 10^{6} ; \mathrm{p}<0.01\right)$.

\section{IN VITRO FUNCTION OF LEUCOCYTES \\ Chemotactic migration}

Random migration by leucocytes in Hank's balanced salt solution from patients with ulcerative colitis was reduced compared with healthy volunteers (Fig. 2). This was found using the leading front method (ulcerative colitis: median 75 um; healthy volunteers: $97 \mathrm{um} ; \mathrm{p}<0.01$ ) as well as the chemotactic index (ulcerative colitis: median 36; healthy volunteers: $74, p<0.01$ ). If leucocytes were suspended in autologous plasma no differences were found.

The chemotactic migration towards casein is summarised in Fig. 3. No differences were found between patients with ulcerative colitis and the healthy volunteers by the leading front method. Measured by the chemotactic index leucocytes from patients with ulcerative colitis exhibited reduced migration in plasma (ulcerative colitis: median 133; healthy volunteers: $176 ; p<0.01$ ) as well as in Hank's balanced salt solution (ulcerative colitis: median 177; healthy volunteers: $166 ; \mathrm{p}<0.01$ ) compared with healthy volunteers.

The migration in Boyden chambers was not correlated to the leucocyte mobilisation or to the clinical activity.

\section{Phagocytosis}

Figure 4 summarises the serum independent and the serum dependent phagocytosis. No differences were found between the groups studied. Serum dependent phagocytosis shows a trend towards increased phagocytosis in ulcerative colitis

Table 3 Relative proportion of leucocytes accumulating in chambers in ulcerative colitis (N:20) and healthy volunteers (N:21)

\begin{tabular}{|c|c|c|c|c|}
\hline \multirow{2}{*}{$\begin{array}{l}\text { Hours after start } \\
\text { of skin window }\end{array}$} & \multicolumn{2}{|c|}{ Neutrophil granulocytes } & \multirow{2}{*}{$\begin{array}{l}\text { Lymphocytes } \\
(\%)\end{array}$} & \multirow{2}{*}{$\begin{array}{l}\text { Macrophages } \\
\text { (\%) }\end{array}$} \\
\hline & $(\%)$ & Mean nucl. segments & & \\
\hline $10-12$ & & & & \\
\hline $\begin{array}{l}\text { Ulcerative colitis } \\
\text { Healthy volunteers }\end{array}$ & $\begin{array}{l}94 \cdot 5(83-97) \\
94 \quad(85-99)\end{array}$ & $\begin{array}{l}3 \cdot 0(2 \cdot 8-3 \cdot 3)^{*} \\
3 \cdot 2(2 \cdot 9-3 \cdot 4)\end{array}$ & $\begin{array}{l}0 \cdot 25(0-1) \\
1 \quad(0-5)\end{array}$ & $\begin{array}{ll}5 \cdot 5 & (2 \cdot 5-16 \cdot 5) \\
4 & (1-13)\end{array}$ \\
\hline $\begin{array}{l}24-28 \\
\text { Ulcerative colitis } \\
\text { Healthy volunteers }\end{array}$ & $\begin{array}{l}99 \cdot 5(96 \cdot 5-100) \\
97(91-100)\end{array}$ & $\begin{array}{l}3 \cdot 0(2 \cdot 8-3 \cdot 4)^{*} \\
3 \cdot 2(3 \cdot 0-3 \cdot 6)\end{array}$ & $\begin{array}{ll}0 & (0-0 \cdot 5) \\
0 & (0-2)\end{array}$ & $\begin{array}{l}0.75(0-2 \cdot 5) \\
1.5(0-7)\end{array}$ \\
\hline
\end{tabular}

Median value and observed range are given. ${ }^{*} \mathrm{p}<0 \cdot 01$. 
Micrometer
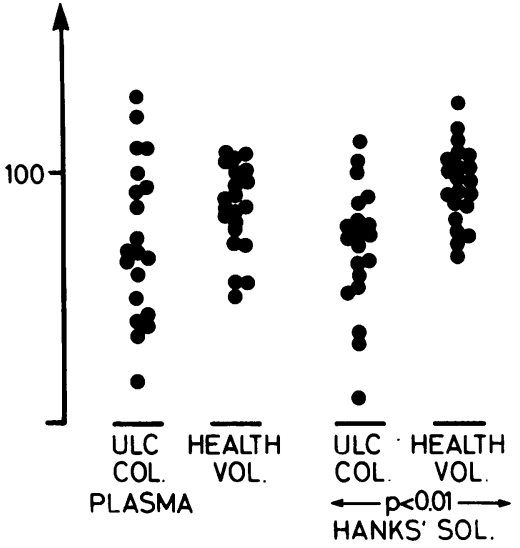

\section{Chemotactic index}

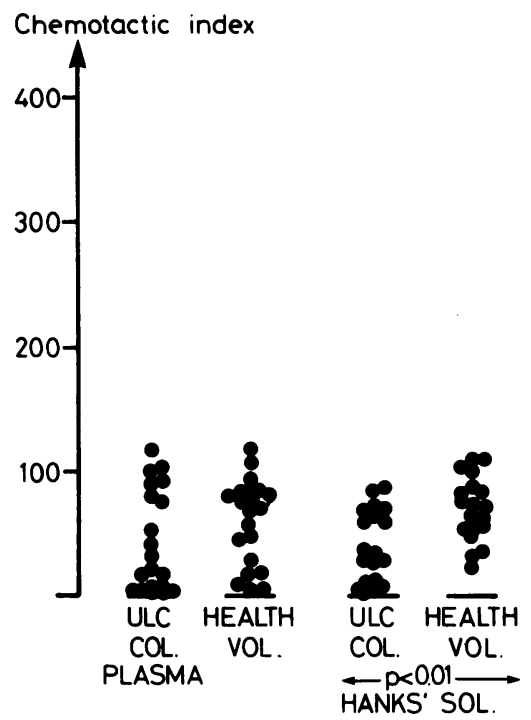

Fig. 2 Random migration in vitro by blood leucocytes. Observed values by the leading front (top) and the chemotactic index (bottom).

compared with healthy volunteers (ulcerative colitis: $0.232 \mathrm{mg}$ oil $/ \mathrm{min} / 10^{7}$ phagocytes; healthy volunteers: $0.194 \mathrm{mg}$ oil $/ \mathrm{min} / 10^{7}$ phagocytes; $0.05<\mathrm{p}<0 \cdot 1)$. Phagocytosis was not correlated with clinical activity, in vitro migration, or leucocyte mobilisation.

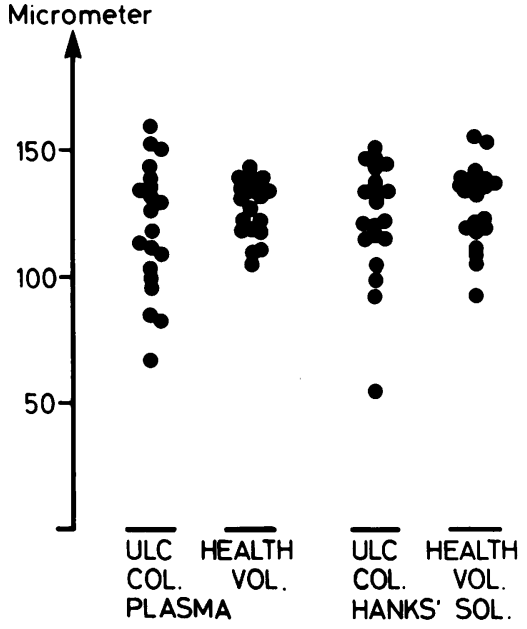

Chemotactic index

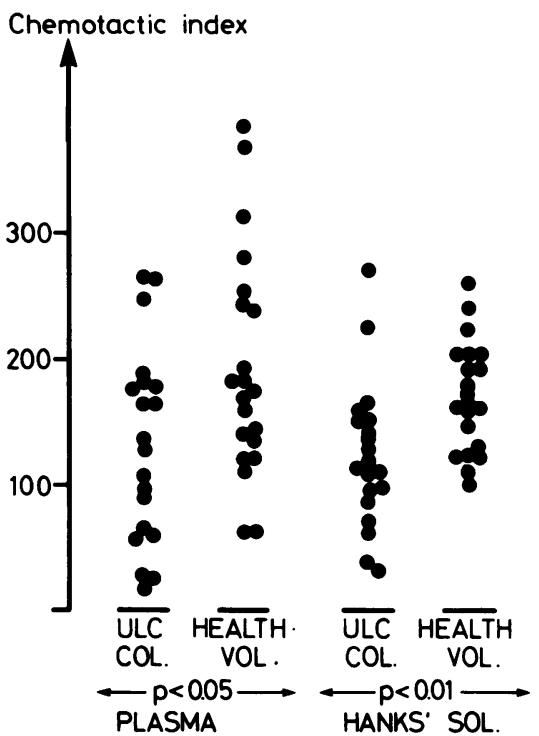

Fig. 3 Chemotactic response in vitro to casein. Results of the leading front method (top) and the chemotactic index (bottom).

Nitro blue tetrazolium reduction

Nitro blue tetrazolium reduction was increased by resting leucocytes from patients with ulcerative colitis (median $0.2373 \mathrm{E}_{580 \mathrm{~mm}} / 8 \mathrm{~min} / 10^{7}$ phagocytes) compared with controls (median $0.0874 \mathrm{E}_{580 \mathrm{~nm}} / 8$ $\min / 10^{7}$ phagocytes; $\mathrm{p}<0 \cdot 01$ ). 
Mg oil min-1
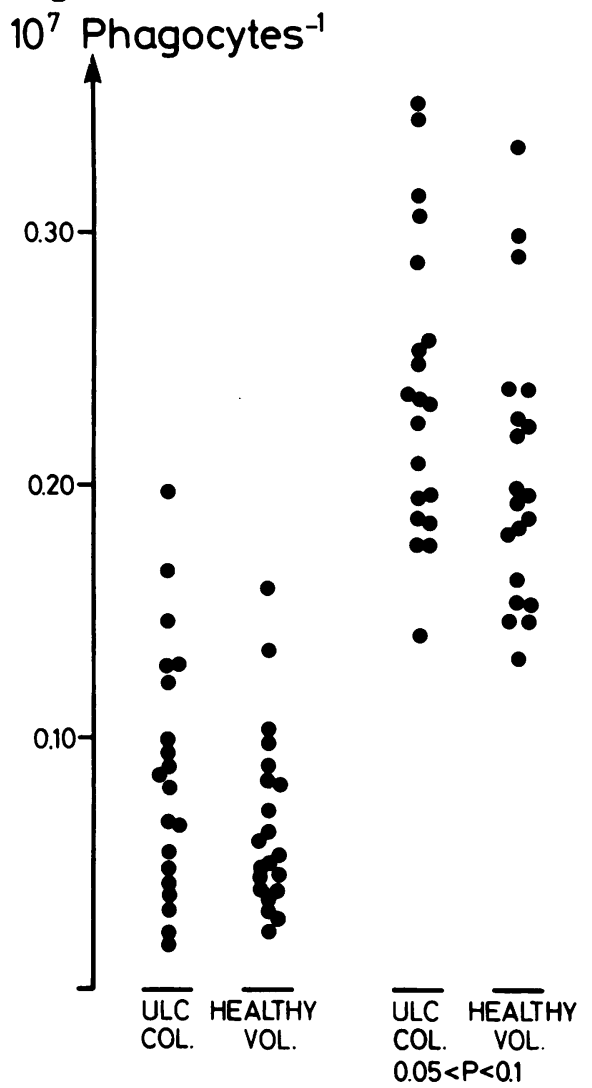

Serum independent Phagocytosis.
Serum dependent Phagocytosis

Fig. 4 Serum independent and serum dependent phagocytosis of paraffin oil emulsions by patients with ulcerative colitis and healthy volunteers.

No differences were found in the nitro blue tetrazolium reduction during phagocytosis (Fig. 5).

\section{Discussion}

The present study demonstrates a reduced mobilisation of leucocytes to skin windows and a reduced in vitro migration in patients with ulcerative colitis. The skin window is a model of the inflammatory reaction reflecting mobilistion of leucocytes from the peripheral blood. ${ }^{12}$ The mobilisation depends on humoral and on cellular factors.

Patients with ulcerative colitis mobilised leucocytes in normal numbers immediately after
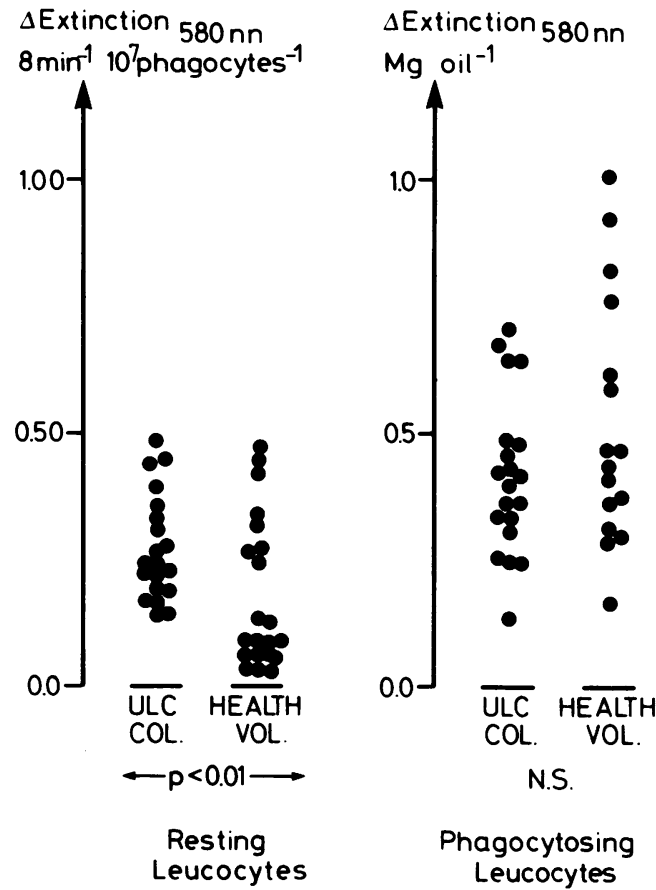

Fig. 5 Nitro blue tetrazolium reduction by resting and phagocytosing leucocytes from patients with ulcerative colitis and healthy volunteers.

eliciting the inflammatory reaction. This indicates that the initial events in the inflammatory reaction are intact - namely, the release of inflammatory mediators and chemotactic agents. A reduced mobilisation occurs after this period. A possible explanation is exhaustion of locally produced chemotactic factors. A reduced amount of complement factors locally has previously been proposed as a cause of diminished leucocyte accumulation. ${ }^{14} \mathrm{~A}$ normal mobilisation has been found in ulcerative colitis ${ }^{15}$ within the first 24 hours if the chamber medium is not removed; this indicates that factors may be generated in the chambers restoring the mobilisation.

Reduced migratory activity of the leucocytes is also a possible explanation for the reduced mobilisation, although no correlations were found between the in vivo mobilisation and the in vitro migration. Whether this reflects lack of sensitivity of the methods applied or implies that more complex mechanisms are active is uncertain.

Other inflammatory diseases are also associated with a reduced in vivo mobilisation including 
Crohn's disease ${ }^{16}$ sarcoidosis, ${ }^{17}$, and in the postoperative state. ${ }^{18}$ The kinetics of the mobilisation in ulcerative colitis resembles that of patients with sarcoidosis and after herniotomy. ${ }^{16} 18$ In contrast, patients with Crohn's disease mobilise leucocytes in low numbers even immediately after the inflammatory reaction is elicited.

The reduced mobilisation in ulcerative colitis may therefore reflect changes secondary to the inflammatory process.

Chemotactic function of leucocytes in ulcerative colitis was reduced, and this was in agreement with previous findings. ${ }^{19} \mathrm{~A}$ reduced chemotactic function has been found in rheumatoid arthritis, ${ }^{20}$ systemic lupus erythomatosus, ${ }^{21}$ sarcoidosis,${ }^{17}$ and bacterial infections. ${ }^{22}$ Antigen-antibody complexes occur frequently in ulcerative colitis ${ }^{34}$ and have been proposed to inactivate leucocyte chemotaxis. ${ }^{20}$ The reduced chemotaxis in ulcerative colitis may therefore be the result of previous ingestion of complexes.

Phagocytosis was normal in ulcerative colitis being in accordance with previous findings. ${ }^{23}$ The serum opsonins required for opsonisation of paraffin oil emulsions are C $3 \mathrm{~b}$ and the alternate pathway of the complement system. ${ }^{24}$ Normal or slightly raised serum dependent phagocytosis indicates a functionally intact alternate pathway and $\mathrm{C} 3 \mathrm{~b}$, although these factors are known to be activated in ulcerative colitis. ${ }^{25}$

The nitro blue tetrazolium reduction by resting leucocytes was increased and confirms previous finding by the slide technique. ${ }^{26}$ This reduction reflects generation of potentially tissue damaging substances as superoxides. ${ }^{72} 28$ Increased nitro blue tetrazolium reduction has also been associated with the presence of bacterial products and antigenantibody complexes. ${ }^{29}$ The finding of this increased reduction and reduced chemotaxis may therefore support the concept of circulating complexes in ulcerative colitis.

In conclusion, patients with ulcerative colitis exhibit reduced in vivo mobilisation and in vitro chemotaxis of leucocytes and increased generation of superoxides as indicated by the nitro blue tetrazolium reduction. The importance of this altered inflammatory reaction and generation of tissue damaging agents for maintaining the inflammatory process is not clear. Lysosomal release from neutrophilic granulocytes in the early lesion of ulcerative colitis ${ }^{9}$ points to a change in the function of the exudative neutrophilic granulocyte of possible importance for the pathogenic mechanism.

The skilful assistance of AL Poulsen, H Kaargaard, and $\mathrm{H}$ Furhauge is gratefully acknowledged. This study was supported in part by the Danish Medical Research Council (no. 512-7257) and by the Johan and Hanne Weimann neé Seedorffs Foundation.

\section{References}

1 Thomas P, Jewell DP, eds. Clinical gastrointestinal immunology. Oxford: Blackwell, 1977.

2 Marcussen H, Nerup J. Fluorescent anti-colon and organ specific antibodies in ulcerative colitis. Scand J Gastroenterol 1973; 8: 9-15.

3 Hodgson HJF, Potter J, Jewell DP. Immune complexes in ulcerative colitis and Crohn's disease. Clin Exp Immunol 1977; 29: 187-96.

4 Nielsen H, Binder V, Daugharty H, Svehag S-E. Circulating immune complexes in ulcerative colitis. I. Correlation to disease activity. Clin Exp Immunol 1978; 31: 72-80.

5 Bendixen G. Specific inhibition of the in vitro migration of leucocytes in ulcerative colitis. Scand $J$ Gastroenterol 1967; 2: 214-21.

6 Hunt PS, Trotter S. The in vitro action of lymphocytes on autologous colon epithelial cells in ulcerative colitis. Aust NZ J Surg 1975; 45: 214-19.

7 Weissmann G, Smolen JE, Hoffstein S. Polymorphonuclear leucocytes as secretory organs of inflammation. J Invest Dermatol 1978; 71: 95-99.

8 Dobbins OW. Colonic epithelial cells and the polymorphonuclear leucocytes in ulcerative colitis. An electron-microscopic study. Digestive Dis 1975; 20: 236-52.

9 Gebbers J, Otto HF. Immunohisto- and ultracytochemical observations on the early lesion in ulcerative colitis. Gut 1978; 19: 989.

10 Binder V. Cell density in lamina propria of the colon. A quantitative method applied to normal subjects and ulcerative colitis patients. Scand J Gastroenterol 1970; 5: 485-90.

11 Harvey RF, Bradshaw JM. A simple index of Crohn's disease activity. Lancet 1980; 8167: 514 .

12 Wandall JH. Leucocyte mobilization to skin lesions. Studies using a chamber technique in healthy volunteers. Acta Pathol Mircrobiol Scand (C) 1980; 88: $255-63$.

13 Wandall JH. Function of polymorphonuclear neutrophilic leucocytes. Comparison of leucocytes from blood and exudate in healthy volunteers. Acta Pathol Microbiol Immunol Scand (C) 1982; 90: 7-13.

14 Lew DP, Despont J-P, Perrin LH, Aguado M-T, Lambert PH, Waldvogel FA. Demonstration of a local exhaustion of complement components and of an enzymatic degradation of immunoglobulins in pleural empyema: A possible factor favouring the persistence of local bacterial infections. Clin Exp Immunol 1980; 42: 506-14.

15 Elmgreen J, Binder V. The chemotactic function of leucocytes in ulcerative colitis. Scand J Gastroenterol (in press). 
16 Wandall JH, Binder V. Leucocyte function in Crohn's disease. Studies on mobilisation using a quantitative skin window technique and on the function of circulating polymorphonuclear leucocytes in vitro. Gut 1982; 23: 173-80.

17 Gange RW, Black MM, Carrington P, McKerron R. Defective neutrophil migration in sarcoidosis. Lancet 1977, 8034: 379-81.

18 Wandall JH, Binder V. Function of neutrophil granulocytes during and immediately after surgical trauma. Br J Surg 1978; 65: 354.

19 Binder V, Riis P. The leucocyte chemotactic function in patients with ulcerative colitis. Scand J Gastroenterol 1977; 12: 141-4.

20 Mowat AG, Baum J. Chemotaxis of polymorphonuclear leucocytes from patients with rheumatoid arthritis. J Clin Invest 1971; 50: 2541-9.

21 Clark RA, Kimball HR, Decker JL. Neutrophil chemotaxis in systemic lupus erythematosus. Ann Rheum Dis 1974; 33: 167-72.

22 Mowat AG, Baum J. Polymorphonuclear leucocytes chemotaxis from patients with bacterial infections. $\mathrm{Br}$ Med J 1971; 3: 617-9.

23 Krause U. Michäelson G, Juhlin L. Skin reactivity and phagocytic activity of neutrophil leucocytes in Crohn's disease and ulcerative colitis. Scand J Gastroenterol 1973; 13: 71-5.

24 Stossel TP, Alper CA, Rosen FS. Serum dependent phagocytosis of paraffin oil emulsified with bacterial lipopolysaccharides. $J$ Exp Med 1973; 137: 690-705.

25 Teisberg $\mathrm{P}$, Gjone E. Humoral immune system in inflammatory bowel disease. Scand J Gastroenterol 1975; 10: 545-9.

26 Ward M, Eastwood MA. The nitro blue terazolium test in Crohn's disease and ulcerative colitis. Digestion 1976; 14: 179-83.

27 Johnston RB, Lehmeyer JE. Elaboration of toxic oxygen by-products by neutrophil granulocytes in a model of immune complex disease. J Clin Invest 1976; 57: $836-41$.

28 Segal AW, Peters TJ. Analytical subcellular fractionation of human granulocytes with reference to the localization of enzymes involved in microbicidal mechanisms. Clin Sci Mol Med 1977; 52: 429-42.

29 Koch C, Høiby, Wiik A. Nitroblue-Tetrazolium (NBT) reduction by human peripheral neutrophil granulocytes in the presence of bacterial antigens. Acta Pathol Microbiol Scand (C) 1975; 83: 144-56. 